\title{
An introduction on below-ground environment and resource acquisition, with special reference on trees. Simulation models should include plant structure and function
}

\author{
Loïc Pagès ${ }^{\mathrm{a},{ }^{*}, \text { Claude Doussan }}{ }^{\mathrm{b}}$ and Gilles Vercambre ${ }^{\mathrm{a}}$ \\ INRA, Centre d'Avignon, a Écophysiologie et Horticulture, 84914 Avignon Cedex 9, France

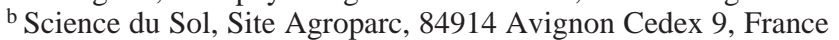

(Received 1 February 1999; accepted 12 July 1999)

\begin{abstract}
Resource acquisition within the soil is a complex process, which consists of several sub-processes involving both the soil and the plant. A brief analysis of the whole system is presented, first by focusing on the components of the system, and then on the successive events. This analysis stresses the diversity and specificity of the components involved, as well as their interactive roles, at several organisation levels, both in space and time. Therefore, a systemic approach using dynamic models is defended in order to gather available knowledge and gain new insight within the whole system. In comparison to many of the traditional modelling approaches, which tended to over-simplify the plant part of the system, some new and promising attempts are presented. These new models give a good illustration of what can be expected to be gained by associating structural and functional characteristics of the plant components.
\end{abstract}

model / root system / soil - plant system / uptake

Résumé - Introduction sur l'environnement souterrain et l'acquisition des ressources, avec références particulières aux arbres. Les modèles de simulation devraient inclure la structure et les fonctions de la plante. L'acquisition des ressources du sol est un processus complexe, que l'on peut subdiviser en plusieurs processus plus élémentaires faisant intervenir conjointement la plante et le sol. Nous faisons une brève analyse de ce système, en insistant d'abord sur ses composants, puis sur les événements successifs. Cette analyse révèle la diversité et la spécificité des composants impliqués, ainsi que leurs rôles interactifs, à plusieurs niveaux d'organisation dans le temps et dans l'espace. Aussi, nous défendons une approche systémique, utilisant la modélisation dynamique, pour synthétiser les connaissances disponibles, et obtenir ainsi un nouvel éclairage sur le système pris dans sa globalité. En comparaison avec les approches de modélisation traditionnelles, qui tendent à simplifier outrageusement la partie plante du système, nous présentons quelque démarches nouvelles et prometteuses. Ces derniers modèles illustrent bien les progrès que l'on peut escompter en associant davantage les caractéristiques structurales et fonctionnelles des composants de la plante.

absorption / modèle / système racinaire / système sol - plante

* Correspondence and reprints

Tel. 04903160 65; Fax.04 903160 28; e-mail: Pages@avignon.inra.fr 


\section{INTRODUCTION}

Resource acquisition within the soil is a complex process, which involves several sub-processes occurring both in the soil and in the plant. Our aim is not to make here an exhaustive tour on this very large subject, on which several more specialised reviews have been written (e.g. [9] and [19], on water uptake; [1] and [12], on nutrient uptake).

Here we intend giving a short introduction to the subject, from a certain point of view, and with particular emphasis on trees. For this purpose, we make a brief analysis, presenting firstly the different actors of the play with their major specific characteristics, and secondly the scenario, by considering the main steps in water and nutrient movement in the soil and the plant.

In the second part, we focus on the modelling requirements for the staging, i.e. for getting an integrated representation of the whole system, by giving to each actor its specific interactive role in the whole system.

For investigating such complex systems, dynamic models are useful tools. It is worth noting that models have been used for many years in this domain, at least since 1960 (see for example the review from Barber [1]). However, most of the models have almost completely neglected the representation of the plant and its root system. This may be because they have been developed mainly by soil physicists, and because of the difficulties related to the observation and representation of the root system. In order to improve such models, with the objective to give more precise answers on when, where, and how much uptake occurs, it is necessary to include a more detailed model of the plant (and especially the root system) structure and function. Through some examples of recent work, we shall see how the representation of the structure-function variations within the root system can modify our quantitative approach to resource acquisition.

\section{THE ACTORS}

\subsection{Resources}

Resources which are taken from the below-ground environment are numerous, and diverse. The first important distinction is between water and mineral nutrients, whose properties are very different. Water is the support or the vector for ions. Ions can move with water by mass flow, or by diffusion.

Considering diffusion, it is important to note that large differences exist in ion mobility, depending mainly on their interaction with the solid phase of the soil. These differences lead to the definition of an apparent diffusion coefficient, with variations greater than 2 orders of magnitude, between mobile ions, such as nitrate, and immobile ones, such as phosphate [14].

The requirements of the plant concerning these resources are also very variable (e.g. macro versus micro-nutrients), and they are more or less buffered, especially in trees, where reserves can play an important role. For instance, there are almost no reserves for water, allowing to buffer only the daily requirements, while reserves for nitrogen can give weeks to months of buffering capacity [18].

These multiple resources interact. An example is given by water, whose content in soil influences both the intensity of mass flow, and the apparent diffusion coefficient for the different ions within the soil.

One of the most important aspects when considering these resources is their heterogeneous distribution, with steep spatial gradients, and strong temporal variations. For water especially, its availability can vary greatly with depth, especially in the surface layers after a dry period. This state is not permanent, since the water profile can be suddenly inverted, just after a significant rain, which will lead to a decrease in water availability with depth. Distribution of nutrients also presents such variations. They often concentrate at the soil surface, and show considerable variations in the horizontal plane (100 to $400 \%$ for $\mathrm{NO}_{3}, \mathrm{NH}_{4}, \mathrm{PO}_{4}$, according to Jackson and Caldwell [13]). This heterogeneous distribution - and thus availability - both in space and time is not specific to natural ecosystems, it may also be reinforced by various cultural techniques, such as fertiliser application or drip fertirrigation (fruit trees). Heterogeneity also exists on a small scale, with, for instance, local enrichments around decomposing organic structures [23], and depletion around functioning roots [14].

\subsection{Soil}

As soil is the containing system for resources, its properties are of prime importance, especially through its interactions with water and nutrients. The hydro-dynamic characteristics of the soil (water release curve, hydraulic conductivity) are known to be highly important variables for the water uptake process. Concerning interactions with nutrients, the soil's buffering capacity is also an important characteristic, since together with local nutrient concentrations, it defines the dynamics of the local availability of nutrients.

The soil also interacts with the root system. It influences its development, structure, and functioning. 
Temperature, bulk density, and oxygen availability are characteristics of the soil which are of major importance in these development and acquisition processes. These three variables present spatial heterogeneity that primarily determine root growth rate, and also the movement of resources and their uptake rate, since nutrient uptake is an energy-dependent process primarily relying on temperature and oxygen availability within the soil.

Local availability of nutrients is also determined by the biological and chemical activity localised in the rhizosphere. For example, soil micro-organisms, interacting with the roots, play an important part in nutrient mobilisation [12].

\subsection{Plant and root systems}

Even though it seems obvious to say that the plant and the root system play a major role in the acquisition processes, the representation of the plant and root complex as an uptake system has often been neglected [5]. From a geometrical point of view, the root system defines both the potential uptake volume (through its global extension) and the minimal distance from the resource to the root (root density). In addition, the root system presents a number of physiological characteristics affecting uptake.

The characteristics of the root system have often been described using root profiles, which consider variation of root length density versus depth. This type of representation assumes more or less implicitly that the spatial distribution of roots is homogeneous within each horizontal soil layer, that all the roots are identical, and that root connections and transport pathways can be neglected. These simplifications are particularly difficult to assume in most cases, and especially for tree root systems because of the structural characteristics of their root systems. Botanists who have studied tree root systems have on the contrary emphasised the diversity of roots (called heterorhizy), and the high organisation of the root systems [8].

Heterorhizy, which can be defined as the heterogeneity of roots in the root system, concerns many morphological and anatomical criteria which also have functional significance in relation to uptake. For example, the apical diameter of roots can vary by more than one order of magnitude in peach trees [31]. These variations in the apical diameter are associated with high variations in water conductance and radial growth [30]. Mycorhizae can be considered as extending the diversity of roots within the root system.

In addition to between-root variations, ontogenetic gradients exist along the roots $[17,33]$. Recent studies show that the uptake and conductance characteristics of the roots vary greatly according to the position along the root $[3,4,10,26]$. The distal parts of roots present generally high radial permeability and uptake capacity compared to the older proximal parts. These older parts have generally much higher conducting capacities. These variations may reach several orders of magnitude.

Moreover, these variations are not randomly distributed in space, as expected if one considers the organised morphogenetic programme of the plant. The developmental scheme, as well as the connection constraints within the plant, lead to a spatial structure. Roots tend to be clustered in space (e.g. [22]), and young root tips especially tend to be located at particular sites within the whole architecture. Conversely, it is clear that roots that are either woody or old tend to be grouped near the stem, making the stump structure. Spatial clustering of roots has important consequences on water uptake, as shown by Tardieu et al. [27].

In addition to this architectural heterogeneity of the root system, the whole plant functioning also influences the dynamics of water and nutrient uptake, and its distribution within the root system. For instance, the restriction in the availability for carbohydrates can influence the temporal pattern of nutrient uptake, and its between root distribution. For example, Thaler and Pagès [28] have shown that the fine roots are more sensitive to carbohydrate restrictions than the large ones.

\section{THE SCENARIO}

Another complementary point of view that can be developed on resource acquisition deals with the scenario, i.e. the sequence of events which occurs during the whole process. Three different phases can be distinguished, involving the different actors. During the first phase resources reach the root surface (supply to the root surface), either by their own movement or because of root growth. During the second phase resources pass from the root surface into the xylem vessels (uptake sensu stricto). The third phase sees resources transported within the plant and assimilated, either in the root or the shoot system (transport and assimilation).

\subsection{Supply to the root surface}

The result of this first important phase, which occurs exclusively within the soil, is the meeting between the resource and the absorbing root.

Root growth is very important regarding the foraging of the soil resources, especially for the less mobile ones. 
Table I. Relative importance of the different processes leading to resource supply to the root in the case of a maize crop (after Barber, 1984).

\begin{tabular}{lcccc}
\hline Nutrient & Amount need & Interception & Mass flow & Diffusion \\
\hline $\mathrm{N}$ & 190 & 2 & 150 & 38 \\
$\mathrm{P}$ & 40 & 1 & 2 & 37 \\
$\mathrm{~K}$ & 195 & 4 & 35 & 156 \\
$\mathrm{Ca}$ & 40 & 60 & 150 & 0 \\
\hline
\end{tabular}

All data in $\mathrm{kg} / \mathrm{ha}$.

Growth is dependent on soil characteristics, which are more or less favourable (e.g. temperature, oxygen availability, mechanical impedance), and also on root type (heterorhizy) since, in the same medium, some roots can grow up to several $\mathrm{cm}$ per day while others will exhibit a much lower growth rate and a short growth duration (e.g. [16]).

Water transport is related to the hydro-dynamic characteristics of the soil (water release curve, and hydraulic conductivity) and depend on the soil texture, structure, and water content. The hydraulic conductivity can exhibit a steep decrease, up to several orders of magnitude, so that water transport in the soil becomes probably the major bottleneck of resource acquisition in dry soils, reinforcing the drought effect. Nutrient transport can be achieved by the two concurrent processes of diffusion and mass flow. The balance between these mechanisms depends on the resource and on the water regime during the growing season. An example is given in table $I$ for a standard maize crop (from Barber [1]).

The gradients of water and nutrient availability around the roots constitute the main driving force for their movement. Here is the link with the second step.

\subsection{Uptake sensu stricto}

Water uptake is generally considered as passive, due to water potential gradients between the external and internal medium. In this physical formalism, which is generally accepted, the proportionality coefficient between the flux and the gradient is the radial conductance. This radial conductance varies with differentiation and ageing of tissues along the root (review by Moreshet and Huck [20]).

For nutrients on the contrary, uptake is generally considered as selective and active, since uptake occurs against the concentration gradient. It requires transporters and energy, whose availability depend on the plant nutrient status, the root type, and on the ontogenet- ic gradient along the root. On avocado trees for instance, Waisel and Eshel [32] have shown strong variations (twofold to tenfold) between- and along-root, for potassium and sodium uptake, in the most apical $5 \mathrm{~cm}$ of the roots.

\subsection{Transport and assimilation}

During this third step, water and nutrients are transported and used (either assimilated, or evaporated).

Since most of the transport occurs in the xylem vessels, its resistance network is of prime importance. The variations of axial resistance in the root system of peach trees have been shown to be highly correlated to the diameter variations of roots ([30] figure 1). Radial growth, which is the major process by which roots can increase their axial conductance in dicotyledonous species, seems to be highly co-ordinated within the root systems. It results in close relationships between the root sections of mother roots and the sum of root sections of their daughter roots ([25, 29, 30] figure 2).

The use of the absorbed products is also an important process to consider, since it modifies the plant status and so the plant demand. For water, the storage capacities are very low. The amount of water stored in peach trees and used during the day reaches only $10 \%$ of the total daily

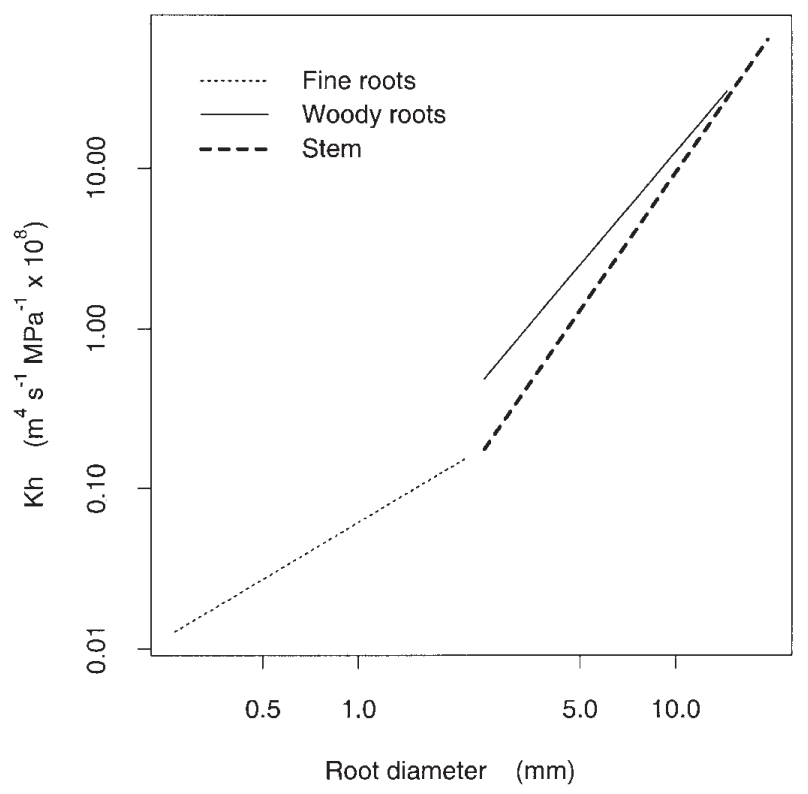

Figure 1. Variations of axial water conductance versus diameter in peach tree roots (after [30]). 


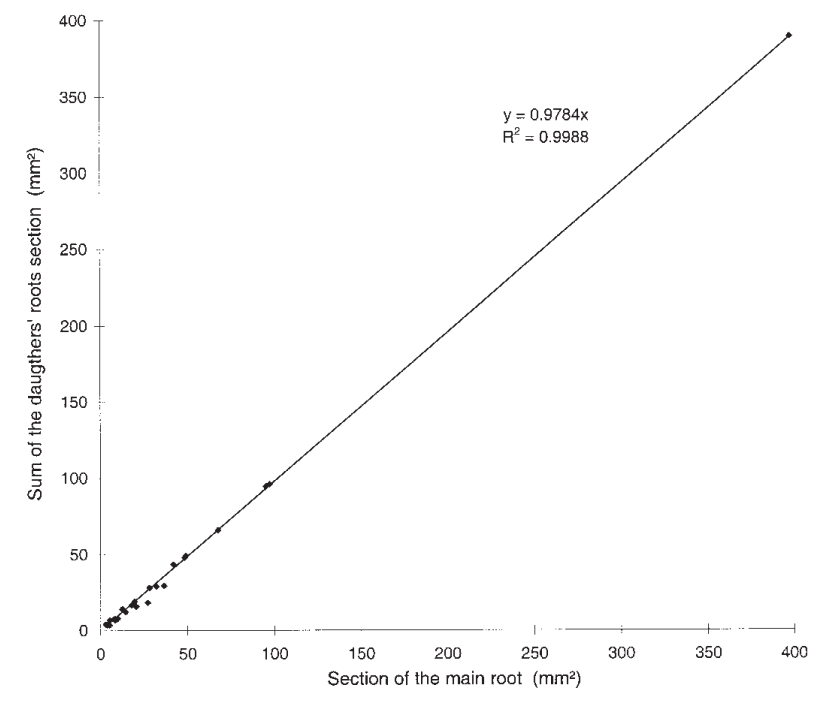

Figure 2. Relationship between the root section area between mother and daughter roots in peach tree root system (after [30]).

transpiration [24]. For nutrients, the definition of plant status is far more complex since it is related to growth dynamics and storage capacities which can be much more important.

Finally, we would like to underline that even though a distinction could be made between these 3 successive processes of resource acquisition, their interactions should be kept in mind, and needs to be modelled. Thus, the distribution of entering water and nutrient fluxes is not fixed. It is a dynamic field, resulting at each moment, of: the distribution of resource availability in the soil; the root system development through the alteration of its geometrical, topological, and ontogenetic characteristics; and the fluctuation of the plant demand propagated through its uptake sites. The possible adaptation of the plant to a heterogeneous environment has been shown by many observations and experiments. Among them, Drew and Saker [7] showed both the morphological and functional plasticity of barley plants cultivated in several layers of nutrient solution, containing or not containing nitrate. Not only the lateral roots grew faster and were more branched in the enriched layers, but their uptake rate also increased, resulting in a globally optimised uptake system.

\section{THE STAGING}

Dynamic simulation models are necessary tools for the staging, or for synthesising the knowledge about these components interacting through multiple processes, in order to get prediction or new insights concerning the whole complex system. To simplify, we have distinguished what we call the "classical models", which have been developed from 1960 onwards (e.g. [1, 9, 11, 19, $21]$ ), and more recent approaches, which integrated the plant structure and function to a greater extent.

\subsection{Classical models}

Detailed reviews have been made about these "classical models", devoted to water uptake [9, 19] or nutrient uptake [1]. Even if they differ in their design, because they are associated to various objectives and plants, these models share a common feature: the over-simplified representation of the plant and its root system. Most of these models have focused on the soil and resource components, considering only the first step of the global process: the supply to the root via the water and nutrient transport. The roots are represented relative to the soil, using a soil-related variable, the root length density. This synthetic variable tries to quantify merely the colonisation of the soil layer.

It is important to note that this approach has been developed mainly for annual crops, and particularly cereals and grasses, which have a particular strategy of root growth characterised by dense and continuously recolonising root systems. For tree ecosystems, the problem differs greatly, since trees (at least dicotyledonous) are much larger and at the same time their root system is less dense, presenting also a typical heterorhizy. Therefore, the assumption of an homogeneous and undifferentiated root length density is no longer acceptable for tree ecosystems.

\subsection{Structure-function models}

Some attempts have been made recently to improve the uptake models, especially for water uptake, by including a more realistic representation of the plant.

The non-uniform distribution of roots in soil was considered by Lafolie et al. [15] who proposed a two-dimensional water flow model for a set of unevenly distributed roots. In this case, the root water potential was assumed to be uniform throughout the root system.

Later on, Clausnitzer and Hopmans [2] suggest merging a whole plant model describing the detailed threedimensional architecture of the root system, with a soil water flow model. Root water uptake is represented by a three-dimensional sink function, calculated from the root tips locations, and assuming that only root tips are active 


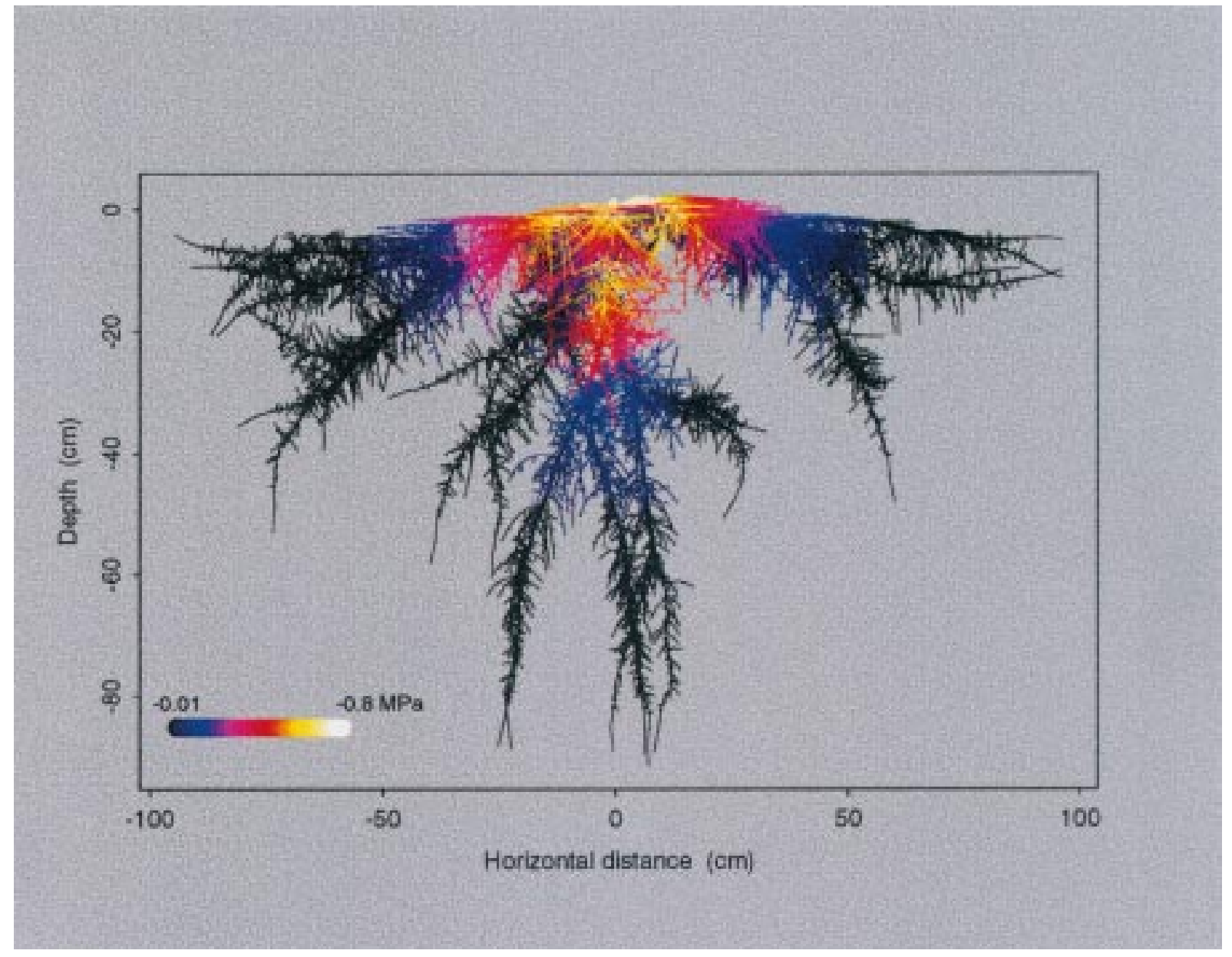

Figure 3. Distribution of the water potential in the peach tree root system, as calculated by a hydraulic model of the root system [5]. Data concerning the water conductance are from Vercambre et al. [30].

in the uptake. The dynamics of the plant demand is also taken into account and shared between the roots.

To circumvent the arbitrary hypothesis that the water potential is uniform within the root system, or that only root tips absorb water, Doussan et al. ([5] and [6]) suggested modelling the hydraulic architecture of the root system. This model merges the architectural modelling of the root system with a hydraulic model, considering radial and axial water conductances at the root segment level (figure 3). With this formalism and particular conductance data, it is possible to model the distribution of water potentials and fluxes within the root system, for a given set of external conditions. For example, using conductance data of peach trees, Vercambre et al. [30] could quantify the water potential gradients as well as the local fluxes in the root system. This model illustrates how structural and functional information can be merged on a local scale, in order to give a global functioning scheme which cannot be inferred without such a model.

\section{CONCLUSION}

Acquisition of resources within the soil environment is a complex process, because it involves a network of interactions between multiple components. These components have specific behaviours, which need to be modelled in order to preserve the integrity of the global 
system. Thus, models should mix different formalisms, for representing at the same time physical processes (e.g. Darcy's law) and biological ones (e.g. root growth).

These models should also succeed in the integration of several organisation levels, from the plant level (e.g. nutrient status) to the root tip level (e.g. uptake characteristics), and several time scales (e.g. day for water, week or month for some nutrients).

For different reasons, such as the search for simplicity, the selection of the major limiting processes in particular situations, or the limited programming and calculation power, models have focused on a limited part of the system, namely the soil. In the future, considerable progress in modelling the resource acquisition can be expected from a better consideration of the plant. Including the plant in these models means including global functional processes, and also its local characteristics, especially the specific architecture of the acquisition system. Many recent works have been done which concern both this architecture and its local functional characteristics.

\section{REFERENCES}

[1] Barber S.A., Soil Nutrient Bioavailability: A Mechanistic Approach. 2nd ed. John Wiley \& Sons, New York, 1984.

[2] Clausnitzer V., Hopmans J.W., Simultaneous modeling of transient three-dimensional root growth and soil water flow, Plant Soil 164 (1994), 299-314.

[3] Cruz C., Lips S.H., Dartins-Lonçao M.A., Uptake regions of inorganic nitrogen in roots of seedlings, Physiol. Plant. 95 (1995) 167-175.

[4] Clarkson D.T., Sanderson J., Russel R.S., Ion uptake and root age, Nature 220 (1968) 805-806.

[5] Doussan C., Pagès L., Vercambre G., Modelling the hydraulic architecture of root systems: An integrated approach of water absorption. I. Model description, Ann. Bot. 81 (1998) 213-223.

[6] Doussan C., Vercambre G., Pagès L., Modelling the hydraulic architecture of root systems: An integrated approach of water absorption. II. Distribution of conductances and consequences, Ann. Bot. 81 (1998) 225-232.

[7] Drew M.C., Saker L.R., Nutrient supply and the growth of Barley. II. Localized, compensatory increases in lateral root growth and rates of nitrate uptake when nitrate supply is restricted to only part of the root system, J. Exp. Bot. 26 (1974) 79-90.

[8] Eshel A., Waisel Y, Multiform and multifunction of various constituents of one root system, in: Plant roots, the hidden half 2nd Ed.. Waisel Y, Eshel A., Kafkafi U. (Eds.). Deker, New-York, 1996, pp. 175-192.
[9] Feddes R.A., Kabat J.T., Bronswijk J.J.B., Halbertsma J., Modelling soil water dynamics in the unsaturated zone, State Art. J. Hydrol. 100 (1988) 69-111.

[10] Frensch J., Hsia T.C., Steudle E., Water and solute transport along developing Maize roots, Planta 198 (1996) 69111.

[11] Gardner W.R., Dynamic aspects of water availability to plants, Soil Sci. 89 (1960) 63-73.

[12] Hinsinger P., How do plant roots acquire mineral nutrients? Chemical processes involved in the rhizosphere, Adv. Agron. 64 (1998) 225-265.

[13] Jackson T.C., Caldwell M.B., Modeling the root water potential and soil-roots water transport in the two-dimensional case. I. Presentation of the model, Soil Sci. Soc Am. J. 55 (1993) 1203-1212.

[14] Jungk A., Dynamics of nutrient movement at the soilroot interface, in: Plant roots. The hidden half 2nd Ed. Waisel Y., Eshel A., Kafkafi (Eds.). Marcel Dekker, Inc., New-York, 1996, pp. 529-556.

[15] Lafolie F., Bruckler L., Tardieu F., Modeling the root water potential and soil-roots water transport in the two-dimensional case. I. Presentation of the model, Soil Sci. Soc Am. J. 55 (1991) 1203-1212.

[16] Le Roux Y., Pagès L., Développement et polymorphisme racinaire chez de jeunes semis d'hévéa (Hevea brasiliensis), Can. J. Bot. 72 (1994) 924-932.

[17] Lüttge E., Klugge M., Bauer G., Botanique. TecDoc Paris, 1992.

[18] Millard P., Ecophysiology of the internal cycling of nitrogen for tree growth. Z. Planzenernähr., Bodenk. 159 (1996) 1-10.

[19] Molz F.J., Models of water transport in the soil-plant system: A review, Water Resour. Res. 23 (1981) 1346-1356.

[20] Moreshet S., Huck M.G., Dynamics of water permeability, in: Plant roots. The hidden half. Waisel Y., Eshel A., Kafkafi (Eds.), Marcel Dekker, Inc., New-York, 1991, pp. 605626.

[21] Nye P.H., Marriott F.H.C., A theoretical study of the distribution of substances around roots resulting from simultaneous diffusion and mass flow, Plant Soil 3 (1969) 459-472.

[22] Pellerin S., Pagès L., Evaluation in field conditions of a three-dimensional architectural model of the maize root system: comparison of simulated and observed horizontal root maps, Plant Soil 178 (1996) 101-112.

[23] Robinson D., The responses of plants to non-uniform supplies of nutrients, New Phytol. 127 (1994) 635-674.

[24] Simonneau T., Habib R., Goutouly, J.-P., Huguet J.-G., Diurnal changes in stem diameter depend upon variations in water content: direct evidence in peach trees, J. exp. Bot. 44 (1993) 615-621.

[25] Spek L.Y., Van Noordwijk M., Proximal root diameter as predictor of total root size for fractal branching. II. Numerical model, Plant Soil 164 (1994) 119-127.

[26] Steudle E., Peterson C.A., How does water get through roots? J. exp. Bot. 49 (1998) 775-788. 
[27] Tardieu F., Bruckler L., Lafolie F., Root clumping may affect the root water potential and the resistance to soil root water transport, Plant Soil 140 (1992) 291-301.

[28] Thaler P., Pagès L., Root apical diameter and root elongation rate of rubber seedlings (Hevea brasiliensis) show parallel responses to photoassimilate availability, Physiol. Plant. 97 (1996) 365-371.

[29] Van Noordwijk M., Spek L.Y., De Willigen P., Proximal root diameter as predictor of total root size for fractal branching. I. Theory, Plant Soil 164 (1994) 107-117.

[30] Vercambre G., Doussan C., Pagès L., Habib R., Distribution of hydraulic conductance in peach tree root system, Implication for water extraction, Plant Soil (1999) (submitted).
[31] Vercambre G., Pagès L., Architecture racinaire du pêcher en conditions de verger. Utilisation d'un modèle pour lier des observations statiques et simuler une dynamique de mise en place, in: Architecture et modélisation en Arboriculture fruitière, $11^{\mathrm{e}}$ Colloque sur les Recherches Fruitières, INRA-CTIFL, Montpellier, 05-06/03/98, 1998, pp. 286-292.

[32] Waisel Y., Eshel A., Differences in ion uptake among roots of various kinds, J. Plant. Nutr. 15 (1992) 945-958.

[33] Wang X.L., McCully M.E., Canny M.J., The branch roots of Zea. IV. The maturation and openness of xylem conduits in first-order branches of soil-grown roots, New. Phytol. 126 (1994) 21-29. 